\title{
Elevated Cytosolic Calcium in the Growth Cone Inhibits Neurite Elongation in Neuroblastoma Cells: Correlation of Behavioral States with Cytosolic Calcium Concentration
}

\author{
R. Angus Silver, Angela G. Lamb, and Stephen R. Bolsover \\ Department of Physiology, University College London, London WC1E 6BT, United Kingdom
}

\begin{abstract}
Schubert (1984) and Kater et al. (1988) have suggested that motility and growth at the neuronal growth cone is activated by an increase of cytosolic free calcium concentration $\left(\left[\mathrm{Ca}^{2+}\right]\right.$ ) above the levels found in quiescent growth cones. In order to test this model, we have used a digital imaging fluorescence microscope together with injection of the fluorescent indicator dye Fura-2 to measure $\left[\mathrm{Ca}^{2+}\right]_{i}$ in growth cones of a mammalian sympathetic neuron, the N1E-115 neuroblastoma cell. The behavior of individual growth cones, together with spontaneously varying levels of $\left[\mathrm{Ca}^{2+}\right]$, within the growth cone, were monitored for periods of up to several hours. $\left[\mathrm{Ca}^{2+}\right]$ in motile, advancing growth cones was low and equal to $\left[\mathrm{Ca}^{2+}\right]$ in quiescent growth cones. Higher values of $\left[\mathrm{Ca}^{2+}\right]_{1}$ were found in motile growth cones that were not advancing, suggesting that a small elevation of $\left[\mathrm{Ca}^{2+}\right]$ inhibits neurite extension. A further rise of $\left[\mathrm{Ca}^{2+}\right]_{1}$ above the level found in motile, nonadvancing growth cones appeared to inhibit motility and cause retraction of the growth cone back towards the cell body. Spatial gradients of $\left[\mathrm{Ca}^{2+}\right]$, within the growth cone were small and, where statistically significant, $\left[\mathrm{Ca}^{2+}\right]_{\text {, }}$ was lower by 5-10 $\mathrm{nM}$ in motile regions. Our results are incompatible with the model that a rise of $\left[\mathrm{Ca}^{2+}\right]_{1}$ is responsible for activating quiescent growth cones; however, our results suggest that in active growth cones $\left[\mathrm{Ca}^{2+}\right]_{1}$ can regulate morphology and behavior.
\end{abstract}

Growth cones, the motile tips of elongating neurites, show a complex and rapidly changing morphology, extending and then retracting long, thin filopodia (Argiro et al., 1985) or flat, visually featureless veils (Tosney and Wessels, 1983) over the substrate. The surface of the growth cone bears complex motile ruffles (Connolly et al., 1985). The movement of filopodia, veils, and ruffles upon the growth cone is termed motility. The growth cone merges at its base into the neurite, which contains longitudinal bundles of microtubules that constrain the neurite into a regular, cylindrical shape (Matus, 1988).

Growth at the growth cone consists of advance at 2 locations.

Received Nov. 21, 1988; revised Mar. 10, 1989; accepted Apr. 14, 1989.

This work was supported by the Wellcome Trust, the Medical Research Council of the United Kingdom, and the SmithKline (1982) Foundation. We wish to thank Dr. Michael Dickens for the gift of purified actin, and Drs. David Allen, David Attwell, Boris Barbour, Lynn Bindman, Dennis Bray, Peter Mobbs, and Michael Whitaker for useful criticism.

Correspondence should be addressed to Stephen R. Bolsover, Department of Physiology, University College London, Gower Street, London WC1E 6BT, United Kingdom.

Copyright @ 1989 Society for Neuroscience $0270-6474 / 89 / 114007-14 \$ 02.00 / 0$
The leading edge of the growth cone is pulled forward by the tension in filopodia (Bray, 1987) or moves forward by extending veils (Goldberg and Burmeister, 1986). The boundary between the neurite and the growth cone moves forward through an extension of the microtubule/neurofilament cytoskeleton (Goldberg and Burmeister, 1986), either by addition of monomers at the neurite/growth cone boundary (Bambury et al., 1986) or by mass forward movement of microtubules and neurofilaments (Lasek, 1982).

The growth cone is acutely sensitive to its environment and can orient to gradients of substrate adhesiveness (Hammarback et al., 1985), to electric fields (McCaig, 1988), or to gradients of agonist in the bathing medium (Gundersen and Barrett, 1980). Growth can be stimulated or inhibited by particular agonists (Greene and Shooter, 1980; McCobb et al., 1988). It is likely that at least some of the control that the environment exerts on the growth cone is mediated by changes in the concentration of intracellular messengers, including $\left[\mathrm{Ca}^{2+}\right]_{i}$ (Schubert, 1984). However, the role of $\left[\mathrm{Ca}^{2+}\right]_{i}$ at the growth cone is very unclear. Schubert (1984) has suggested that an increase of $\left[\mathrm{Ca}^{2+}\right]_{i}$ promotes motility and growth, while Cohan and Kater (1986) proposed the opposite view: an increase in $\left[\mathrm{Ca}^{2+}\right]_{\mathrm{i}}$ opposes axon growth. Kater et al. (1988) have recently proposed a synthesis. They suggest that both neurite elongation and motility at the growth cone require $\left[\mathrm{Ca}^{2+}\right]_{i}$, but these 2 aspects of growth have different $\left[\mathrm{Ca}^{2+}\right]_{i}$ optima. In their model, quiescent growth cones, showing neither neurite elongation nor motility, have a low $\left[\mathrm{Ca}^{2+}\right]_{\mathrm{i}}$. A rise of $\left[\mathrm{Ca}^{2+}\right]_{\mathrm{i}}$ into the range optimal for growth stimulates both motility and neurite elongation. A further rise of $\left[\mathrm{Ca}^{21}\right]_{\mathrm{i}}$ stops neurite elongation; motility, with a higher $\left[\mathrm{Ca}^{2+}\right]_{\mathrm{i}}$ optimum, continues. Last, $\left[\mathrm{Ca}^{2+}\right]_{\mathrm{i}}$ may rise further into a range incompatible with either neurite elongation or motility.

Recent work has suggested a possible role for spatial variation of $\left[\mathrm{Ca}^{2+}\right]_{\mathrm{i}}$ within the growth cone. Connor (1986) found local regions of high $\left[\mathrm{Ca}^{2+}\right]_{\mathrm{i}}$ at the base of extending filopodia. However, he was unable to rule out the possibility that these apparent high $-\left[\mathrm{Ca}^{2+}\right]_{\mathrm{i}}$ regions were an artefact of the dye-loading technique that he used. Goldberg (1988) found that local extracellular application of $\mathrm{Ca}^{2+}$ induced vcil extension at the point of application of $\mathrm{Ca}^{2+}$ and suggested that veil extension might occur from regions of the growth cone in which $\left[\mathrm{Ca}^{2+}\right]_{i}$ was high.

In order to distinguish between the conflicting theories as to the role of $\left[\mathrm{Ca}^{2+}\right]_{\mathrm{i}}$ at the growth cone and to examine the possible role of spatial variation of $\left[\mathrm{Ca}^{2+}\right]_{i}$ within the growth cone, we have simultaneously measured motility, growth, and the spatial distribution of $\left[\mathrm{Ca}^{2+}\right]_{\mathrm{i}}$ in growth cones of differentiating N1E115 cells. The growth cones at the tips of extending neurites 
show motile behavior very similar to motility of primary sympathetic neurons (Bolsover et al., 1988). The large size of neuroblastoma cells allows us to inject fura- 2 directly, without introducing the errors associated with ester loading (Cobbold and Rink, 1987) and allows resolution of possible gradients of $\left[\mathrm{Ca}^{2+}\right]_{i}$ across the growth cone.

\section{Materials and Methods}

N1E-115 neuroblastoma cells were maintained in Dulbecco's modification of Eagle's medium buffered with $1.21 \mathrm{gm} /$ liter $\mathrm{NaHCO}_{3}$ and supplemented with $6 \%$ fetal calf serum in an atmosphere of $5 \% \mathrm{CO}_{2}$ at $36^{\circ} \mathrm{C}$. Cells for $\left[\mathrm{Ca}^{2+}\right]$, measurement were suspended in the same medium and plated onto polylysine-coated glass coverslips. Two days after plating 2\% dimethyl sulfoxide (DMSO) by volume was added to promote differentiation (Kimhi et al., 1976). After 2-6 d in DMSO coverslips were transferred to the stage of an inverted microscope and bathed in differentiation medium in which $10 \mathrm{~mm}$ HEPES replaced $\mathrm{NaHCO}_{3}$. The medium was covered with a layer of paraffin oil (to improve thermal insulation and reduce evaporation) and maintained between 34 and $36^{\circ} \mathrm{C}$.

Individual cell bodies were impaled with a pipette (resistance $20 \mathrm{M} \Omega$ when filled with $2 \mathrm{M} \mathrm{KCl}$ ) containing $10 \mathrm{~mm}$ fura-2 (Molecular Probes, OR), $140 \mathrm{~mm} \mathrm{KCl}$, and $5 \mathrm{~mm}$ HEPES, pH 7.0. Fura-2 was injected by applying pressure to the back of the pipette or by iontophoresis. The pipette was then removed. Fura-2 diffused to growth cones located up to $400 \mu \mathrm{m}$ from the cell body in $10-20 \mathrm{~min}$. The final intracellular concentration of fura- 2 (mean $=390 \mu \mathrm{M}, \mathrm{SD}=250 \mu \mathrm{M}, n=19$ ) was estimated from the fluorescence emitted from the cell body during excitation at $350 \mathrm{~nm}$ divided by the thickness of the cell body (estimated by assuming that the cross section of the cell body at its shortest diameter was a semicircle). False color images of intracellular calcium concentration were produced by digital imaging fluorescence microscopy (Tsien and Poenie, 1986) using a suite of programs adapted from programs purchased from Dr. R. Y. Tsien. Exciting light from a xenon arc lamp passed through 1 of 2 narrow band filters with center wavelengths at 350 and $380 \mathrm{~nm}$ (DF series, Glen Creston, UK) before being directed onto the preparation by a dichroic mirror (DC400, Glen Creston) and microscope objective (100 $\times$ Neofluor, Nikon). Light emitted from fura-2 passed through the dichroic mirror and a broad-band filter of center wavelength $510 \mathrm{~nm}$ (DF510/30, Glen Creston) and was collected by a silicon-intensified target camera (type 5153-7000, COHU, CA). A single fura-2 ratio image took a total of $3 \mathrm{sec}$ to acquire. Fura-2 ratio images are displayed together with transmittcd light images taken at the same microscope magnification. The coverslip upon which the cells were growing often moved during an experiment. We therefore repositioned transmitted light images such that dirt particles on the coverslip superimposed in successive images. Five such dirt particles are indicated with red arrowheads in Figure 1. Fura-2 ratio images were repositioned by the same extent as the transmitted light image closest in time. The images were then cropped such that all images in a particular figure show precisely the same region of the coverslip. To facilitate comparison, a white line is drawn around each fura-2 ratio image to indicate the edge of the corresponding transmitted light image.

The $3 \mathrm{sec}$ taken to acquire a fura-2 ratio image set an absolute limit on the time resolution of these experiments. When images were acquired at the maximum rate, we saw no evidence for spontaneous changes of $\left[\mathrm{Ca}^{2+}\right]_{i}$ on the time scale of seconds; rather, $\left[\mathrm{Ca}^{3+}\right]_{\mathrm{i}}$ changed over the course of tens of minutes. We therefore routinely acquired images at $\geq 10$ min intervals, because exposure to the bright ultraviolet light tended to stop growth and motility (Kater et al., 1986).

Injection of fura- 2 will not attenuate spatial gradients of $\left[\mathrm{Ca}^{2+}\right]_{i \cdot}$. The effective diffusion constant for $\mathrm{Ca}^{2+}$ in nerve cell cytoplasm has been measured as $8.3 \times 10^{-7} \mathrm{~cm}^{2} / \mathrm{sec}$ (Nasi and Tillotson, 1985). After injection of fura- 2 , most of the freely diffusable $\mathrm{Ca}^{2+}$ will be bound to fura- 2 . The effective diffusion constant of fura- 2 inside cells is equal to the value in free solution at $3.6 \times 10^{-7} \mathrm{~cm}^{2} / \mathrm{sec}$ (Baylor and Hollingworth, 1988), approximately half the effective diffusion constant for $\mathrm{Ca}^{2+}$. Thus, injection of fura- 2 might be expected to increase the amplitude of spatial gradients slightly. However, fura-2 injection will not change the direction of $\left[\mathrm{Ca}^{2+}\right]_{\mathrm{i}}$ gradients.

Control experiments. The presence of $2 \%$ DMSO in our differentiation and recording medium might distort calcium levels or calcium gradients In the absence of DMSO, N1E-115 cells extend neurites in the first 2 $\mathrm{d}$ after suspension and replating but then pull in these neurites and reenter the cell cycle. In order to test for an artefact due to DMSO, we measured $\left[\mathrm{Ca}^{2+}\right]_{\mathrm{i}}$ within DMSO-free growth cones during this $2 \mathrm{~d}$ postplating period.

In order to test for possible artefacts due to beam inhomogeneity or spatial variations of growth cone thickness and UV absorbance, we injected the dye 8-aminonaphthalene-1,3,6-trisulfonic acid (ANTS; Molecular Probes, OR), which has similar excitation and emission spectra to fura- 2 but is unaffected by $\mathrm{pH},\left[\mathrm{Ca}^{2+}\right]_{\mathrm{i}}$ or $\left[\mathrm{Mg}^{2+}\right]$, and recorded false color ratio images using the same excitation and barrier filters.

Growth cones, or regions of growth cones, that differ in motility may have different concentrations of either f-actin or g-actin. In order to test for a possible effect of f-actin or g-actin on either the spectrum or $K_{D}$ of fura-2, we measured the excitation spectrum of $1 \mu \mathrm{M}$ fura- 2 in a buffer of $100 \mathrm{~mm} \mathrm{KCl}, 5.67 \mathrm{~mm} \mathrm{CaCl}_{2}, 8 \mathrm{~mm}$ BAPTA (Tsien, 1980), $0.2 \mathrm{~mm}$ mercaptoethanol, $0.2 \mathrm{~mm}$ adenosine triphosphate, and $1 \mathrm{~mm}$ tris(hydroxymethyl)aminomethane, $\mathrm{pH}$ 8.0. In this buffer, approximately $40 \%$ of the fura- 2 was bound to $\mathrm{Ca}^{2+}$, therefore a change of $K_{D}$, or a spectral change of either the free or calcium-bound dye, would change the measured spectrum. However, the presence of g-actin at 1 $\mathrm{mg} / \mathrm{ml}$ had no effect on the spectrum. Addition of spermine to $60 \mu \mathrm{M}$ polymerized the actin (Grant et al., 1983) but did not alter the spectrum.

We examined the effect of introducing fura- 2 into N1E-115 cells by the method of AM loading (Tsien, 1981). Cells were bathed in differentiation medium containing $20 \mu \mathrm{M}$ fura-2 AM (Molecular Probes, OR) for 30-60 min. The medium was then changed to differentiation medium without fura- $2 \mathrm{AM}$ and the cells left at least $90 \mathrm{~min}$. The medium was then changed to recording medium and $\left[\mathrm{Ca}^{2+}\right]_{1}$ measured. For consistency with the experiments of Connor (1986), loading was performed at $36^{\circ} \mathrm{C}$.

All results are given as means $\pm \mathrm{SE} ; p$ valucs are for 2-tailed $t$ test.

Image manipulation. We calculated the ratio $r$ of fluorescence emitted by fura-2 during $350 \mathrm{~nm}$ excitation to fluorescence emitted during 380 $\mathrm{nm}$ excitation as

$$
r=\left(I^{350}-B\right) /\left(I^{380}-B\right)
$$

where $I^{350}=$ fluorescence detected by the camera during $350 \mathrm{~nm}$ excitation; $I^{380}=$ fluorescence detected by the camera during $380 \mathrm{~nm}$ excitation; and $B=$ background signal detected by the camera in the absence of light.

Autofluorescence from the cells was negligible and was not corrected for. The parameter $r$ increases as $\left[\mathrm{Ca}^{2+}\right]_{\mathrm{i}}$ increases (Grynkiewicz et al., 1985). However, the absolute value of $r$ depends on the light source and the transmittance properties of all the components in the optical system; it is therefore unique for each digital imaging fluorescence microscope

Figure 1. Fura-2 ratio imaging of a quiescent growth cone. $A$, Transmitted light image of a growth cone. The time at which this image was acquired is defined at $t=0$. $N$, neurite; $L$, lamellipodium. Five red arrowheads are placed in the same positions in $A$ and $C$ and indicate dirt particles on the coverslip that were used when repositioning the image to correct for coverslip movement. The broad dark regions that have changed position between images $A$ and $C$ are bubbles in the liquid paraffin. $B$, Fura-2 ratio image of the growth conc acquired at $t=27$ min. Colors correspond to $R$ values and hence to $\left[\mathrm{Ca}^{2+}\right]_{\mathrm{i}}$ according to the scale on the spectrum at the left. This scale applies to all the Fura- 2 ratio images shown in this paper. The image appears black where the fluorescent signal was below an arbitrary threshold ( $1 / 8$ of camera saturation). Fluorescence from the thin, narrow neurite was less than this threshold, so that the neurite does not appear in the fura- 2 ratio image. The image is mainly blue, indicating a low [Ca $\left.{ }^{2+}\right]_{i}$ (overall $R=1.32,\left[\mathrm{Ca}^{2+}\right]_{\mathrm{i}}=61 \mathrm{nM}$ ). $C$, Transmitted light image acquired $15 \mathrm{sec}$ after image $B$. Neither the position nor the appearance of the growth cone has changed relative to image $A$. Quiescent growth cones are often rounded and relatively thick, so that the fura-2 ratio image $B$ is broadened because of fluorescence from out-of-focus regions. This phenomenon is not observed in the other images in this paper, in which the growth cones are thinner. 

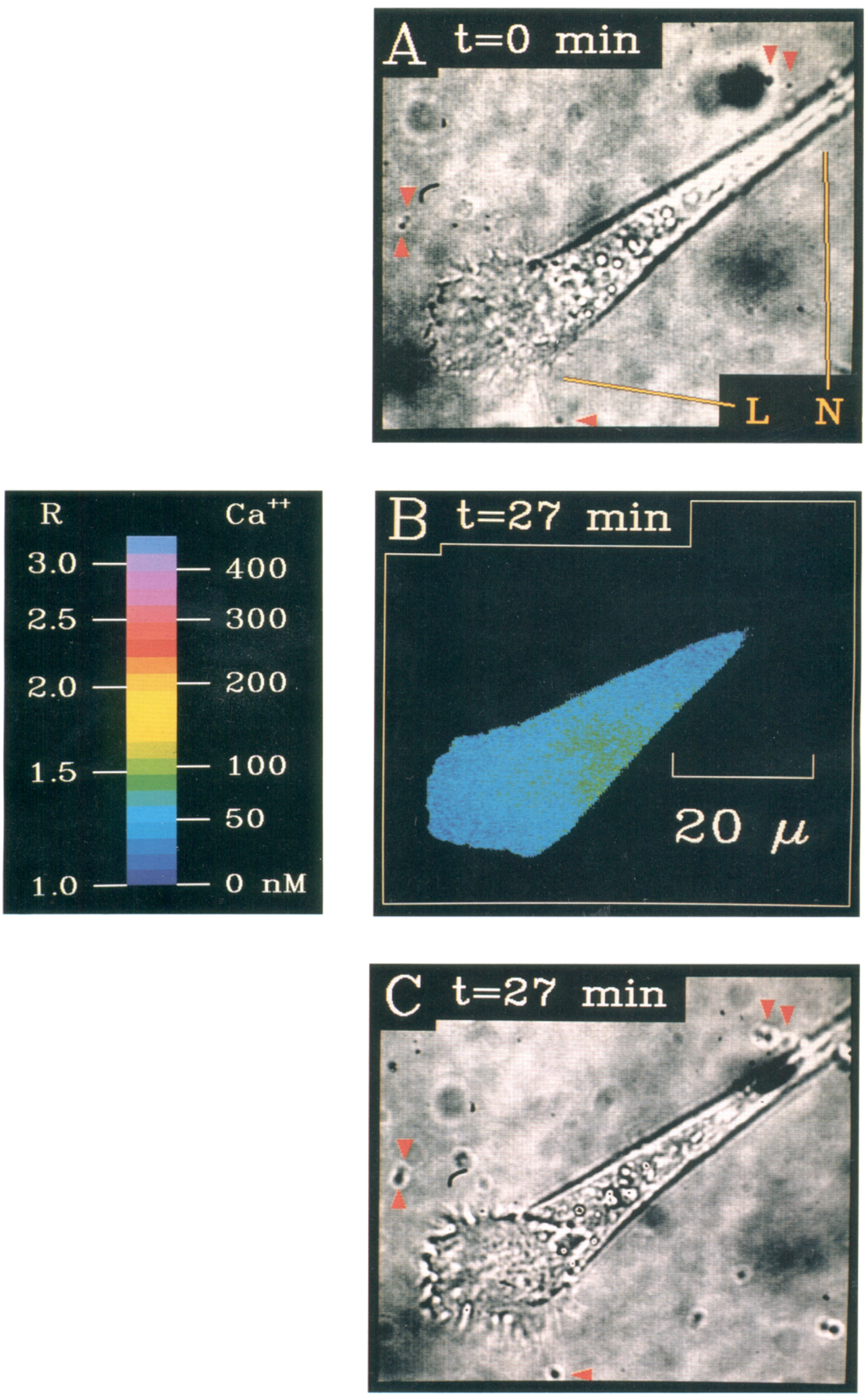

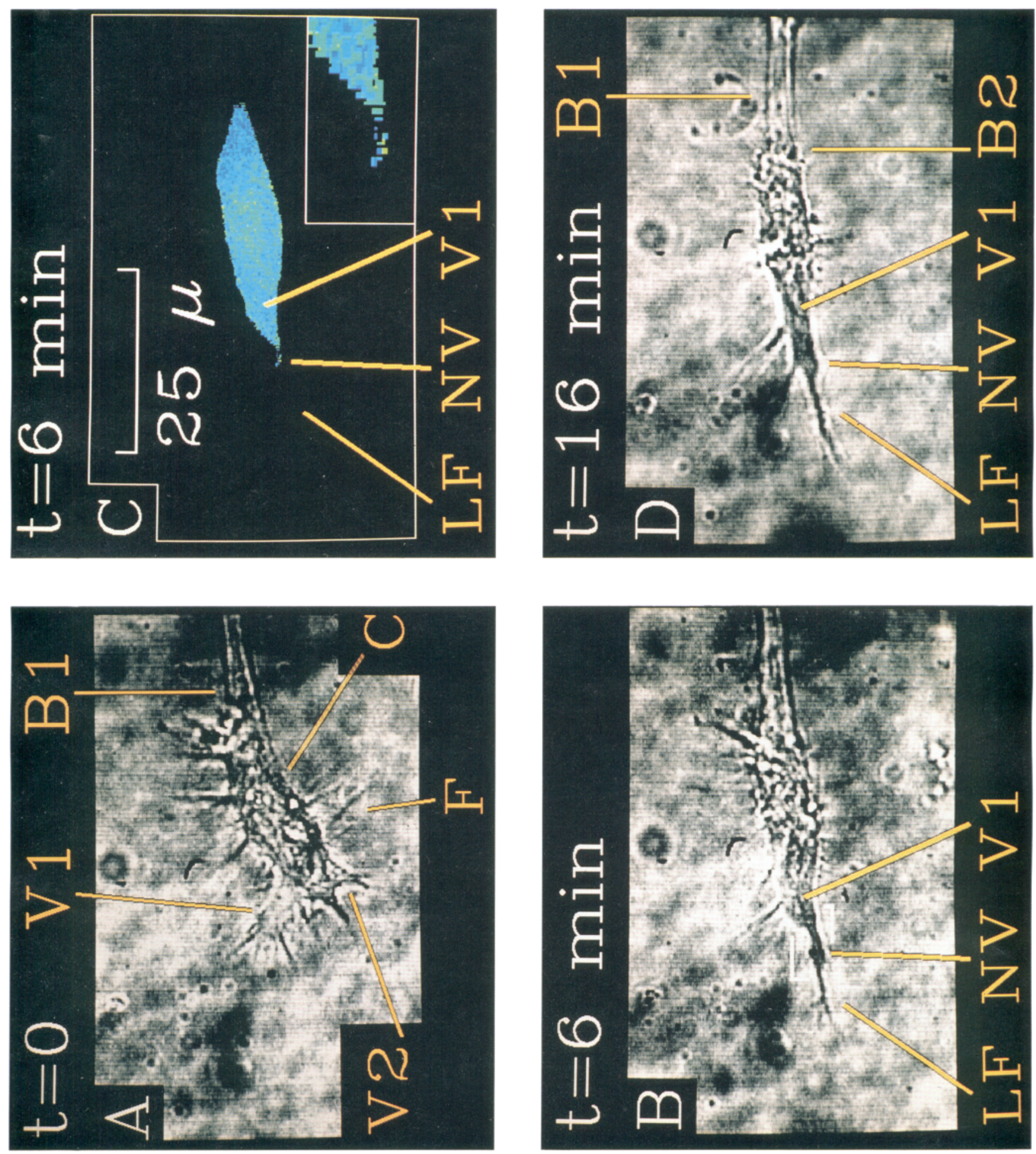
and is not easily comparable with the results of other workers. We therefore state our results as normalized ratios

$$
R=r / r^{\prime}
$$

where $r^{\prime}$ is the ratio measured for a standard $\mathrm{Ca}^{2+}$-free solution containing $20 \mathrm{~mm}$ EGTA, $140 \mathrm{~mm} \mathrm{KCl}, 10 \mathrm{~mm}$ HEPES, pH 7, and 100 $\mu \mathrm{M}$ fura- 2 . When so normalized, saturating $\mathrm{Ca}^{2+}$ solutions give an $R$ value of 21.9. The fura-2 ratio images in this paper are pixel-by-pixel plots of $R$.

Overall $R$ for a particular cell region was calculated as the weighted average of $R$ values of pixels within that region, weighted by the total fluorescence intensity at each pixel. In particular, values of growth cone $R$ were calculated by averaging all those pixels of intensity greater than an arbitrary cutoff ( $1 / 8$ camera saturation) that lay distal to the neurite/ growth cone junction. In order to measure $R$ in a specific localized region of the growth cone, we drew a circle around particular regions on the transmitted light image; we then placed a circle of the same position and radius on the fura- 2 ratio image and calculated the weighted average of $R$ for pixels within the circle.

$\left[\mathrm{Ca}^{2+}\right]_{i}$ in the growth cone was calculated from fura- 2 ratio images. The calcium concentration corresponding to a particular overall $R$ value was calculated according to (Grynkiewicz et al., 1985);

$$
\left[\mathrm{Ca}^{2+}\right]_{\mathrm{i}}=K_{1 / 2}\left[\frac{R-R_{0}}{R_{\text {sat }}-R}\right]
$$

where $R_{\mathrm{o}}=R$ measured for solutions of zero calcium $=1, R_{\mathrm{sat}}=R$ measured for solutions of saturating $\left[\mathrm{Ca}^{2+}\right]_{\mathrm{i}}=21.9, \mathrm{~K}_{1 / 2}=\left[\mathrm{Ca}^{2+}\right]_{\mathrm{i}}$ for which $R$ is midway between $R_{0}$ and $R_{\text {sat }}$, and $=3.9 \mu \mathrm{M}$ at $34^{\circ} \mathrm{C}$, determined using Ca:EGTA buffers

Images of growth cones injected with ANTS were, in the same way, pixel-by-pixel plots of $R$, where $R$ was normalized such that $R=1$ for ANTS in the in vilro $\mathrm{Ca}^{2}$-free standard solution.

\section{Results}

N1E- 115 cells differentiating in the presence of $2 \%$ DMSO Growth cone behavioral states

Growth cones varied widely in size (from $<10 \mu \mathrm{m}$ to $>100 \mu \mathrm{m}$ in width), structural complexity, and rate of change of morphology. Nevertheless, we were able to define 5 behavioral states into which most growth cones could be unequivocally sorted.

1. Quiescent growth cones showed no movement, either of the whole growth cone or of structurcs on the growth cone.

2. Motile, advancing growth cones showed both movement of structures upon the growth cone and forward movement of the neurite/growth cone boundary.

3. Motile, nonadvancing growth cones showed movement of structures upon the growth cone without forward movement of the neurite/growth cone boundary.

4. Flattening growth cones became very thin and usually expanded in area, without forward movement of the neurite/growth cone boundary.

5. Retracting growth cones showed a withdrawal of motile structures into the growth cone followed by a withdrawal of the growth cone towards the cell body.

This classification differs from that used by Cohan et al. (1987) in 2 ways. We subdivide motile growth cones into motile advancing and motile nonad vancing, and we create a new category, flattening. Previous authors have described the behavior we term flattening (e.g., Anglister et al., 1982), but have not defined it as a specific bchavioral catcgory. Figurc 9 summarizes the correlation between behavioral state and growth cone $\left[\mathrm{Ca}^{2+}\right]_{\mathrm{i}}$ for N1E-115 cells in the presence of DMSO.

\section{Injection of fura- 2 does not distort $\left[\mathrm{Ca}^{2+}\right]_{i}$}

We injected relatively high concentrations of fura- 2 in order to achieve sufficient signal from thin growth cones. The concentration of fura-2 in the cell body ranged from 105 to $1037 \mu \mathrm{M}$ in the 19 cells in which it was measured. Fura-2 is a calcium chelator, and thus it might be expected to reduce $\left[\mathrm{Ca}^{2+}\right]_{i}$, with the greatest reduction of $\left[\mathrm{Ca}^{2+}\right]_{\mathrm{i}}$ being seen in those cells with the highest intracellular concentration of fura- 2 . However, cell body $R$ values (mean $=1.46 \pm 0.04,\left[\mathrm{Ca}^{2+}\right]_{\mathrm{i}}=88 \pm 7 \mathrm{nM}$ ) showed no statistical correlation with fura- 2 concentration (correlation coefficient $=-0.10$ ). We therefore do not believe that injection of fura- 2 to the concentrations we used disturbed the ability of the cells to regulate $\left[\mathrm{Ca}^{2+}\right]_{i}$. The distribution of growth cones among the 5 behavioral states was not affected by the amount of fura- 2 injected ( $\chi^{2}$ test on a $2 \times 5$ contingency table, with growth cones divided into the 12 with highest [fura-2], and the 12 with lowest [fura-2], gave $p>0.05$ ). The 5 behavioral states, together with fura- 2 measurements, are described in more detail below.

\section{Quiescent growth cones}

The defining feature of quiescent growth cones was that their appearance did not change over many minutes. Figure 1 illustrates a quiescent growth cone. Each of the 3 images shows the same field at the same magnification. The growth cone consisted of a rounded portion plus a flattened terminal lobe (L). The neurite $(\mathrm{N})$ ran to the cell body, which was out of the field of view. Twenty-seven minutes later (Fig. 1C), the appearance and position of the growth cone had not changed. Figure $1 B$ is a fura-2 ratio image, acquired $15 \mathrm{sec}$ before Figure $1 C$. Colors correspond to $R$ value, and hence to $\left[\mathrm{Ca}^{2+}\right]_{\mathrm{i}}$, as indicated in the scale at the left, which applies to all the fura-2 ratio images in this paper. Low values of $R$ and $\left[\mathrm{Ca}^{2+}\right]_{\mathrm{i}}$ are represented by a blue color. Higher values of $\left[\mathrm{Ca}^{2+}\right]_{i}$ appear respectively as green, then yellow, with the highest values represented as red. The image in Figure $1 B$ is mainly blue, indicating a low value of $\left[\mathrm{Ca}^{2+}\right]_{i}$. This result was obtained consistently: in 8 quiescent growth cones, mean $R$ was $1.29 \pm 0.04,\left[\mathrm{Ca}^{2+}\right]_{\mathrm{i}}=55 \pm 7 \mathrm{nM}$ (see Fig. 9).

$\leftarrow$

Figure 2. Fura-2 ratio imaging of a motile, advancing growth cone. $A$, Transmitted light image of the growth cone. The time at which this image was acquired is defined as $t=0$. The growth cone consists of a central region $(C)$ bearing numerous filopodia $(F)$. At the leading edge, the growth cone bears 2 thin veils $(V 1, V 2) . B 1$, Neurite/growth cone boundary. $B$, Six min later. The lower veil, $V 2$ in $A$, has been retracted. One filopodium has extended dramatically to become a leading filopodium $(L F)$, and a new, thin, featureless veil (NV) is forming at its base. The white cursurs indicates the corners of the area shown enlarged as an insert in $C$. $C$, Fura-2 ratio image acquired 32 sec after image $B$. The image is mainly blue, indicating a low $\left[\mathrm{Ca}^{2+}\right]_{\mathrm{i}}$ (overall $R=1.36,\left[\mathrm{Ca}^{2+}\right]_{\mathrm{i}}=68 \mathrm{nM}$ ). The position of the yellow lines is the same in images $B-D . D, 16 \mathrm{~min}$ after the aquisition of $A$. The leading filopodium has advanced further, while the veil NV has broadened. The older veil $V I$ has lost its thin, featureless appearance, probably because organelles have moved in from the central region of the growth cone (Goldberg and Burmeister, 1986). In the 16 min between the time of acquisition of images $A$ and $D$ the neurite/growth cone boundary has advanced $7 \mu \mathrm{m}$ from B1 to B2. Insert in $C$. Close-up of the area within the white box in $B$. Calcium is resolved within the spreading new veil at the base of the extending filopodium. No spatial gradients of [Ca $\left.{ }^{2+}\right]_{i}$ are seen. Mean $R$ for the isolated pixels is 1.36 , equal to mean $R$ for the entire growth cone. 

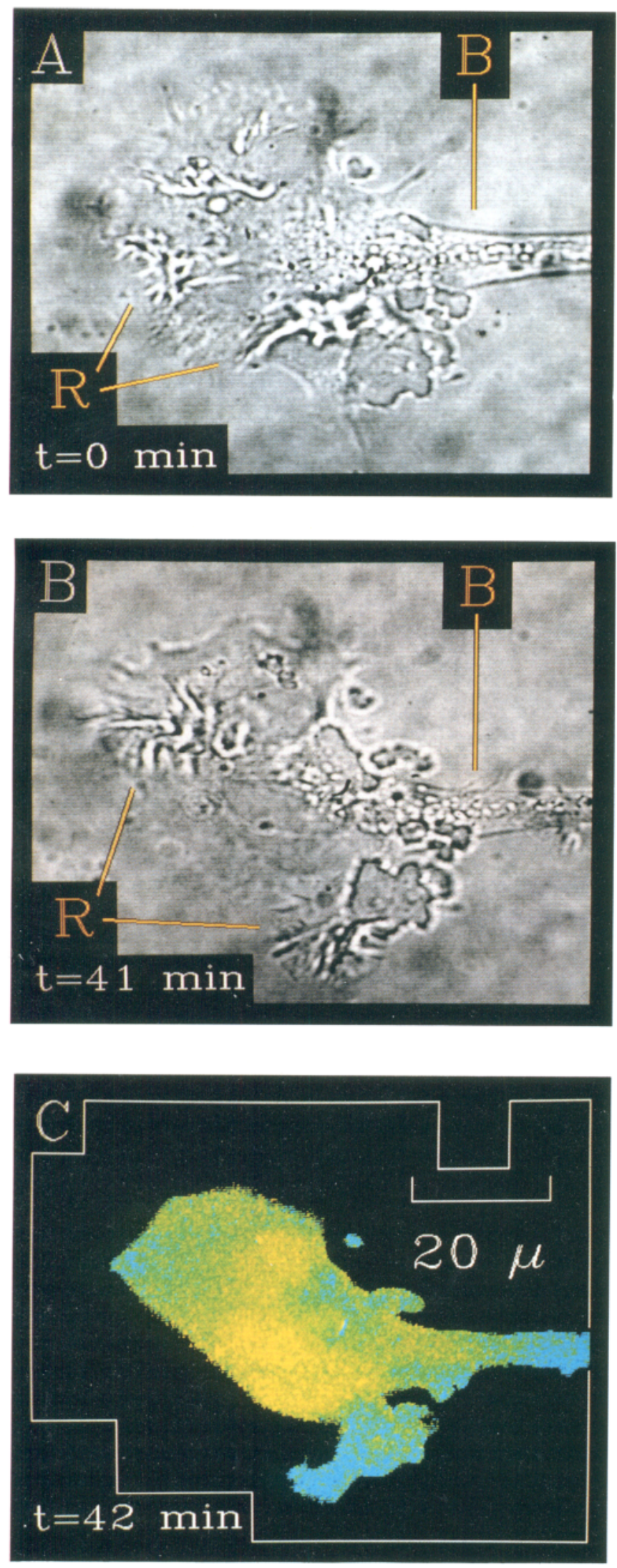

Figure 3. Motile, nonadvancing growth cone. A, Transmitted light image of the growth cone. The time at which this image was acquired is defined as $t=0 . R$, ruffles; $B$, boundary between the neurite and the growth cone. $B$, Transmitted light image acquired at $t=41 \mathrm{~min}$. The appearance of the ruffles $(R)$ has changed, indicating that they are motile.

\section{Motile advancing growth cones}

Motile growth cones changed their appearance dramatically over the course of minutes as filopodia, veils, or ruffles were extended, moved, and retracted. In addition, a subset of motile growth cones showed advancement of the neurite/growth cone boundary at an average of $0.23 \pm 0.06 \mu \mathrm{m} / \mathrm{min}(n=7)$. Figure 2 illustrates one such motile, advancing growth cone. Over 16 min, the growth cone changed appearance dramatically as filopodia and veils were extended; however, the net effect was an advancement of both the leading edge of the growth cone and the neurite/growth cone junction (from B1 in Fig. $2 A$ to B2 in $2 D$ ). The fura- 2 ratio image (Fig. $2 C$ ) was mainly blue, indicating a low $\left[\mathrm{Ca}^{2+}\right]_{\mathrm{i}}$. This result was obtained consistently: In 7 motile, advancing growth cones, mean $R$ was $1.32 \pm 0.03,\left[\mathrm{Ca}^{2+}\right]_{\mathrm{i}}=60$ $\pm 5 \mathrm{nM}$; that is, $\left[\mathrm{Ca}^{2+}\right]_{\mathrm{i}}$ was not significantly different in quiescent and advancing growth cones (Fig. 9).

\section{Motile, nonadvancing growth cones}

Many growth cones exhibited motile behavior such as extension of filopodia and veils, and movement of ruffles, without net advancement of the neurite/growth cone boundary. Figure 3 illustrates one such motile, nonadvancing growth cone. In the 41 min between the acquisition of images $3 \mathrm{~A}$ and $3 \mathrm{~B}$, the appearance of the growth cone changed, principally through movement of 2 highly motile ruffles $(R)$. However, the boundary between the neurite and the growth cone (indicated by the line B) did not advance during this period.

The growth cones of Figures 2 and 3 illustrate the range of motile growth cones observed in neuroblastoma cells, from thin and filopodial to broad and ruffling. However, advancement of the neurite/growth cone junction was not restricted to growth cones of any particular type of motility: We were unable to predict from the appearance of a motile growth cone whether that growth cone would show advancement of the neurite/growth cone boundary. Fura- 2 ratio images were, in contrast, accurate indicators of whether a growth cone would advance. The fura-2 ratio image in Figure $3 C$ appeared mainly green, indicating a higher $\left[\mathrm{Ca}^{2+}\right]_{i}$ than in the motile, advancing growth cone of Figure $2 C$. This result was obtained consistently: In 20 motile, nonadvancing growth cones, mean $R$ was $1.50 \pm 0.02,\left[\mathrm{Ca}^{2+}\right]_{\mathrm{i}}$ $=94 \pm 4 \mathrm{nM}$, very significantly higher than in motile, advancing growth cones $(p<0.001)$ (Fig. 9).

\section{Flattening growth cones}

Motile growth cones occasionally displayed a sequence of behavior that we term flattening. Growth cone thickness decreased, while area usually increased. The margins of the growth cone became more difficult to visualize, presumably because these regions became extremely thin. We estimate both from direct measurements in which we focused on the top and bottom of the growth cone, and from the fall of fluorescent intensity per unit area of growth cone, that growth cone thickness approximately halved. Filopodia were sometimes extended during flattening. Figure 4 illustrates a typical flattening growth cone. In the 21 min between the acquisition of Figure $4 A$ and $B$, the

$\leftarrow$

However, the boundary between the neurite and the growth cone has remained static at $B$. $C$, Fura-2 ratio image acquired $36 \mathrm{sec}$ after image $B$. Overall $R=1.51,\left[\mathrm{Ca}^{2+}\right]_{\mathrm{i}}=97 \mathrm{nM}$. $\left[\mathrm{Ca}^{2+}\right]_{\mathrm{i}}$ appears lower in local regions around the 2 ruffles. $\left[\mathrm{Ca}^{2+}\right]_{i}$ in the upper and lower ruffles was, respectively, 19 and $36 \mathrm{~nm}$ lower than the overall average for the growth cone. 

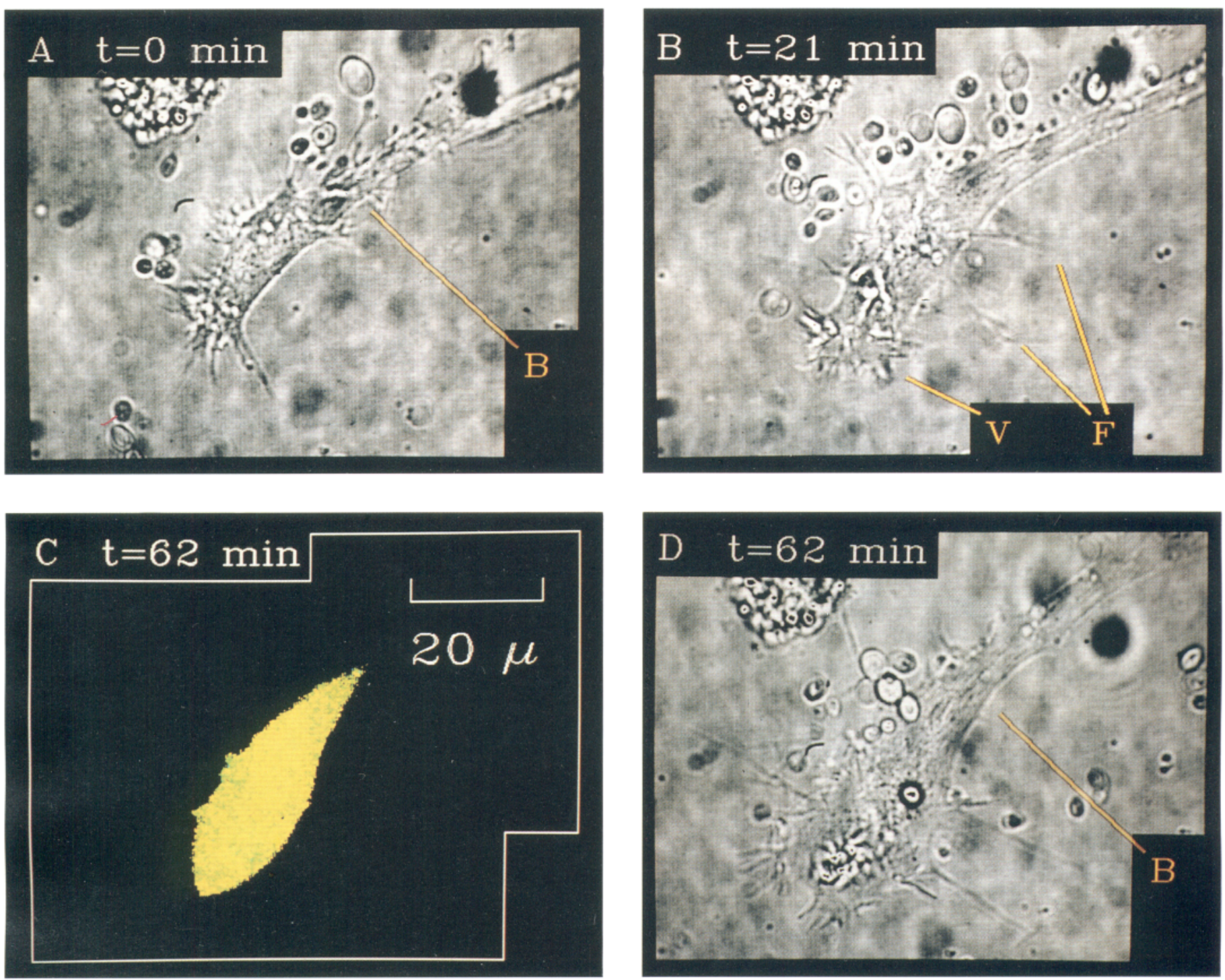

Figure 4. Flattening growth cone. $A$, Transmitted light image of the growth cone. The time at which this image was acquired is defined as $t=0$. $B$, Transmitted light image acquired at $t=21 \mathrm{~min}$. New, long filopodia $(F)$ have been extended in the 21 min since acquisition of image $A$. A veil $(V)$ has extended forward over preexisting filopodia, whose ends protrude from the edge of the veil as "nubbins" (Goldberg and Burmeister, 1986). $C$, Fura-2 ratio image acquired at $t=62 \mathrm{~min}$. Overall $R=1.66,\left[\mathrm{Ca}^{2+}\right]_{\mathrm{i}}=127 \mathrm{~nm}$. $D$, Transmitted light image acquired 32 sec after image $C$ showing further flattening compared with image $B$.

main body of the growth cone became wider, and the edges became less distinct. Furthermore, the growth cone extended new filopodia $(\mathrm{F})$ and a veil $(\mathrm{V})$. In the subsequent $41 \mathrm{~min}$, the area of the growth cone and the envelope of its filopodia continued to increase (Fig. 4D). However, the boundary (B) between the neurite and the growth cone did not advance during the entire $62 \mathrm{~min}$ period. Figure $4 C$ is a fura- 2 ratio image acquired $32 \mathrm{sec}$ before Figure $4 D$. The image was mainly yellow, indicating a higher $\left[\mathrm{Ca}^{2+}\right]_{i}$ than was seen in motile growth cones. This result was obtained consistently: $R$ in flattened growth cones was $1.66 \pm 0.05, n=9,\left[\mathrm{Ca}^{2+}\right]_{\mathrm{i}}=127 \pm 10 \mathrm{nM}$, very significantly higher than in motile nongrowing growth cones $(p$ $<0.005$ ) (Fig. 9). Flattened growth cones were not stable. We followed the subsequent fate of 7 flattened growth cones. In 6 , $\left[\mathrm{Ca}^{2+}\right]_{\mathrm{i}}$ remained high, and the growth cones began retracting (see below). In the last growth cone, $\left[\mathrm{Ca}^{2+}\right]_{\mathrm{i}}$ fell and the growth cone resumed motility.

\section{Retraction}

We observed 9 instances where motile growth cones ceased motility and retracted, often via an intermediate flattening stage. Retraction occurred in 2 phases. In the first phase, motile structures (ruffles, veils, and filopodia) were retracted into the central core of the growth cone. Retraction fibers remained where veils had been retracted. The second phase of retraction consisted of a balling-up of the growth cone together with a mass movement of the growth cone back towards the cell body. Figure 5 illustrates a retracting growth cone. The fura-2 ratio image (Fig. $5 C$ ) is orange, indicating a relatively high $\left[\mathrm{Ca}^{2+}\right]_{i}$. This result was obtained consistently: In 7 retracting growth cones, $R$ was 2.12 $\pm 0.26\left[\mathrm{Ca}^{2+}\right]_{\mathrm{i}}=225 \pm 58 \mathrm{~nm}$ (Fig. 9). Within this wide range of elevated $\left[\mathrm{Ca}^{2+}\right]_{\mathrm{i}}$ values, the lower values $(R=1.62 \pm 0.04$, $n=5 ;\left[\mathrm{Ca}^{2+}\right]_{\mathrm{i}}=119 \pm 9 \mathrm{nM}$ ) were found in growth cones during the retraction of veils and motile fans, while the higher values 

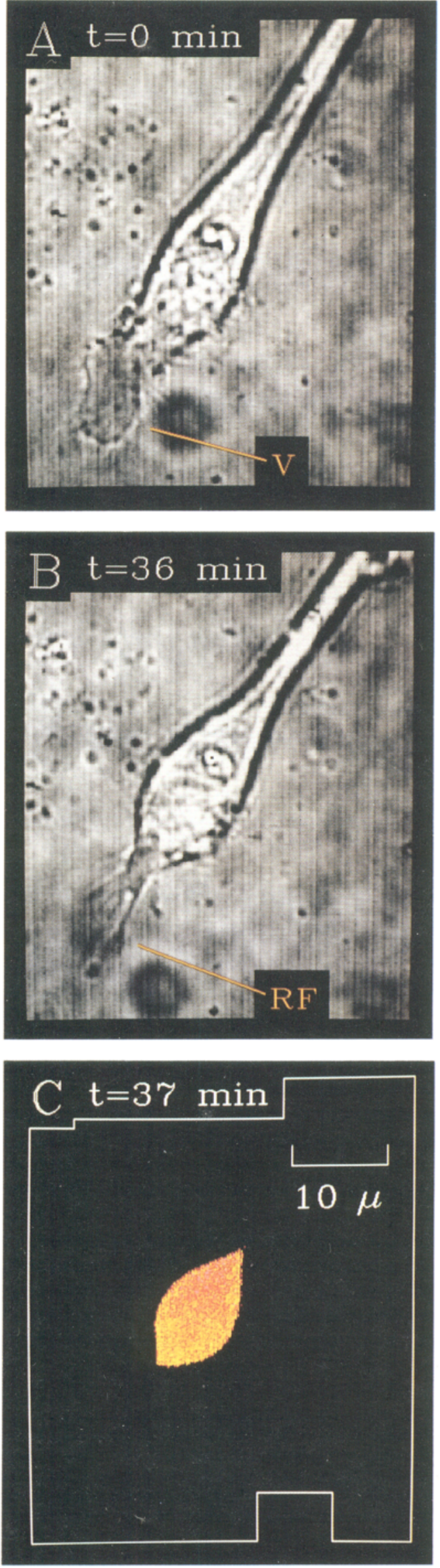

$\left(R=2.59 \pm 0.27, n=5 ;\left[\mathrm{Ca}^{2+}\right]_{\mathrm{i}}=324 \pm 62 \mathrm{nM}\right)$ were found in growth cones that were retracting back towards the cell body.

We observed growth cones to switch between all of the behavioral states, in both directions, except that we never observed a switch out of the quiescent state. As the behavioral state changed, so did $\left[\mathrm{Ca}^{2+}\right]_{\mathrm{i}}$. Figure 6 shows an example of a growth cone that switched from the veil-retracted state to the motile nonadvancing state as $\left[\mathrm{Ca}^{2+}\right]_{\mathrm{i}}$ fell.

\section{Spatial gradients}

Spatial gradients of $R$ value and therefore $\left[\mathrm{Ca}^{2+}\right]_{i}$ within growth cones were always small. The value of $R$, and therefore $\left[\mathrm{Ca}^{2+}\right]_{\mathrm{i}}$, was consistently lower in the growth cone as compared with the cell body $\left(R_{\text {growth cone }}-R_{\text {soma }}=-0.15 \pm 0.06, n=28\right.$, $\left.\left[\mathrm{Ca}^{2+}\right]_{\mathrm{i}, \text { growth cone }}-\left[\mathrm{Ca}^{2+}\right]_{\mathrm{i} \text {, soma }}=-31 \pm 12 \mathrm{nM}\right)$. This difference was not a simple artifact produced by the greater path length or signal amplitude at the cell body, because the difference recorded in cells injected with ANTS, a dye with excitation and emission spectra similar to fura- 2 that is insensitive to $\left[\mathrm{Ca}^{2+}\right]_{\mathrm{i}}$, was much smaller and was of opposite $\operatorname{sign}\left(R_{\text {grown cone }}-R_{\text {soma }}\right.$ $=+0.03 \pm 0.01, n=13)$. However, the slight elevation of $\left[\mathrm{Ca}^{2+}\right]_{\mathrm{i}}$ in the cell body may be a result of local damage caused during injection of fura- 2 into the soma.

We often observed a gradation of $R$ value within the growth cone, with $R$ highest in the center and lower both at the junction with the neurite and at the leading edge. When we averaged across all growth cones, only the leading edge/center difference proved statistically significant $\left(R_{\text {leading edge }}-R_{\text {center }}=-0.04 \pm\right.$ $0.01, n=47, p<0.001)$. This difference corresponded to a calcium gradient of $9 \pm 2 \mathrm{nM}$. No such gradient appeared in growth cones injected with ANTS $\left(R_{\text {leading edge }}-R_{\text {center }}=+0.003\right.$ $\pm 0.004, n=12$ ).

Goldberg (1988) has suggested that advancement of veils may be caused by a local elevation of $\left[\mathrm{Ca}^{2+}\right]_{\mathrm{i}}$. We did not observe raised $\left[\mathrm{Ca}^{2+}\right]_{i}$ within advancing veils; rather, $\left[\mathrm{Ca}^{2+}\right]_{\mathrm{i}}$ was either the same as the average for the whole growth cone (Fig. 2) or very slightly lower. In 6 advancing veils, mean $R_{\text {advancing veil }}-$ $R_{\text {whole growth cone }}$ was $-0.03 \pm 0.01$ ( $\left.p<0.05\right)$, corresponding to a $\left[\mathrm{Ca}^{2+}\right]_{i}$ difference of $8 \mathrm{nM}$. Prominent, discrete ruffles (termed "motile fans" by Bolsover et al., 1988) often showed a locally low $\left[\mathrm{Ca}^{2+}\right]_{\mathrm{i}}$ (e.g., Figs. 3, 6), but the phenomenon was more variable and the difference was not statistically significant $\left(R_{\text {prominent ruffle }}-R_{\text {whole growth cone }}=-0.04 \pm 0.02, n=8\right.$, corresponding to a $\left[\mathrm{Ca}^{2+}\right]_{\mathrm{i}}$ difference of $\left.10 \mathrm{nM}\right)$. The ruffling margins of lamellipodia showed a significantly lower $R\left(R_{\text {ruffling margin }}-\right.$ $R_{\text {whole growth cone }}=-0.04 \pm 0.01, n=7, p<0.01$, corresponding to a $\left[\mathrm{Ca}^{2+}\right]_{\mathrm{i}}$ difference of $10 \mathrm{~nm}$ ), but this gradient was no more pronounced than the general tendency for the leading edge of the growth cone to show a lower $\left[\mathrm{Ca}^{2+}\right]_{i}$.

Freeman and colleagues (1985) have suggested that calcium channels are concentrated in the membrane of filopodia. If such a concentration existed in neuroblastoma cells, then $\left[\mathrm{Ca}^{2+}\right]_{i}$ would be expected to be higher at the filopodial base. We saw no region of elevated $\left[\mathrm{Ca}^{2+}\right]_{i}$ at the base of filopodia (Figs. 2, 4); rather,

Figure 5. Retracting growth cone. A, Transmitted light image of the growth cone. The time at which this image was acquired is defined as $t=0$. $V$, veil. $B$, Transmitted light image acquired at $t=36 \mathrm{~min}$. The veil has retracted, leaving retraction fibers $(R F)$; the growth cone is beginning to move upward, toward the cell body that lies out of the frame at the top. $C$, Fura-2 ratio image acquired $58 \mathrm{sec}$ after image $B$. Overall $R=2.22,\left[\mathrm{Ca}^{2+}\right]_{\mathrm{i}}=246 \mathrm{nM}$. 

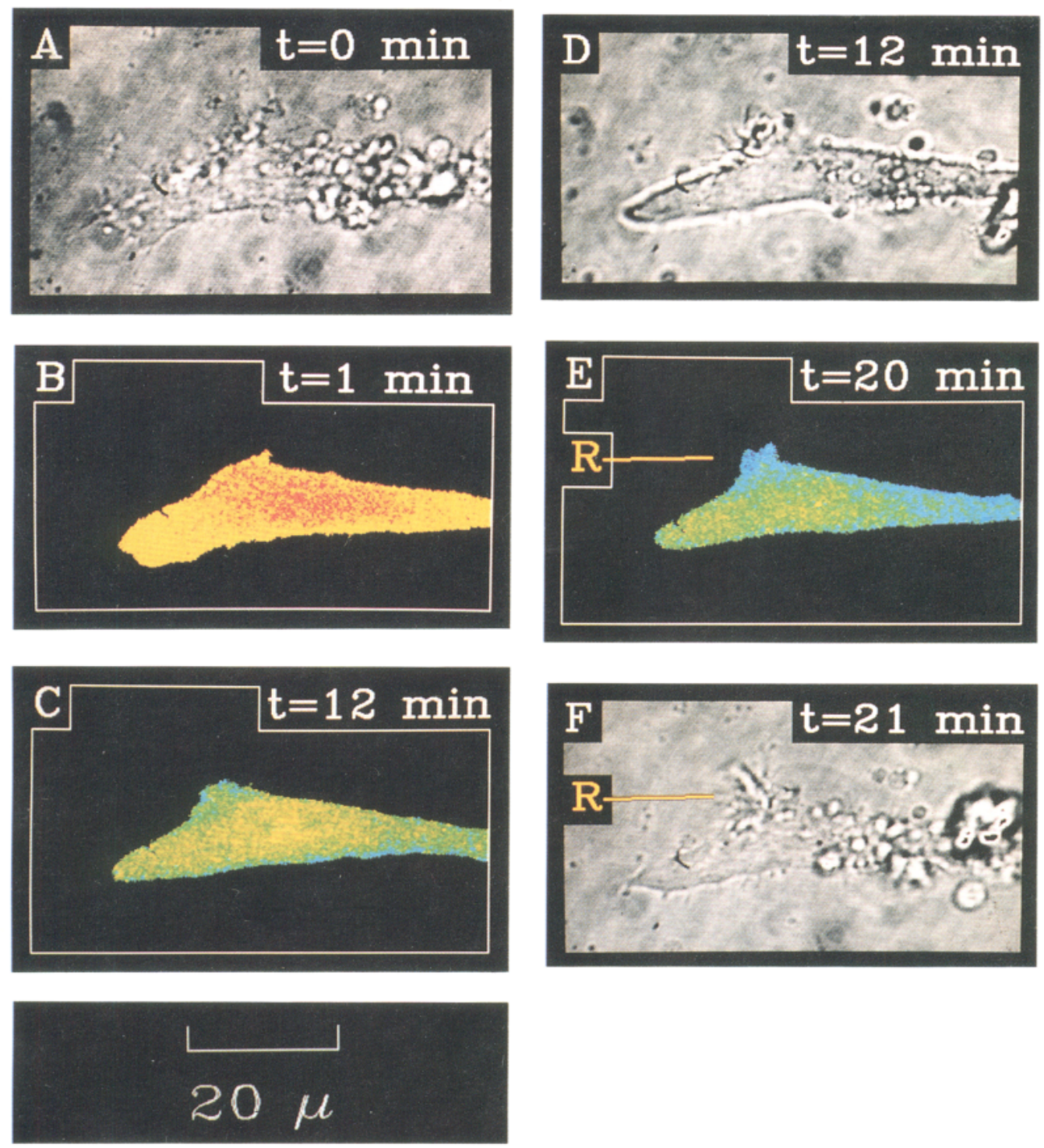

Figure 6. Recovery of motility coincides with a fall of $\left[\mathrm{Ca}^{2+}\right]_{\mathrm{i}}$. The growth cone was monitored for 18 min prior to the acquisition of image $A$, during which it showed behavior intermediate between flattening and retraction. The neurite is obscured by adherent dirt. The time of acquisition of image $A$ is defined as $t=0$. B, Fura-2 ratio image acquired $51 \mathrm{sec}$ after image. $A$. Overall $R=2.01,\left[\mathrm{Ca}^{2+}\right]_{\mathrm{i}}=201 \mathrm{~nm}$. $C$, Fura-2 ratio image acquired at $t=12 \mathrm{~min}$. Overall $R=1.56,\left[\mathrm{Ca}^{2+}\right]_{\mathrm{i}}=108 \mathrm{~nm}$. $D$, Transmitted light image acquired $27 \mathrm{sec}$ after image $C$. $E$, Fura-2 ratio image acquired at $t=20 \mathrm{~min}$. Overall $R=1.46,\left[\mathrm{Ca}^{2+}\right]_{i}=88 \mathrm{~nm}$. $F$. Transmitted light image acquired $60 \mathrm{sec}$ after image $E$. Over the 21 minutes between the acquisition of images $A$ and $F$, a ruffle $(R)$ appeared on the upper edge of the growth cone and extended upwards. The Fura-2 ratio images show a local region of low $\left[\mathrm{Ca}^{2+}\right]_{i}$ at the ruffle. In image $E$, the region corresponding to the ruffle had a $\left[\mathrm{Ca}^{2+}\right]_{i} 27 \mathrm{~nm}$ lower than the overall mean for the growth cone.

$\left[\mathrm{Ca}^{2+}\right]_{\mathrm{i}}$ in these regions was, like other regions of the growth cone margin, slightly lower than the growth cone average $\left(R_{\text {filopodial base }}\right.$ $-R_{\text {whole growth cone }}=-0.08 \pm 0.05, n=8$, not significant, corresponding to a $\left[\mathrm{Ca}^{2+}\right]_{\mathrm{i}}$ difference of $17 \mathrm{nM}$ ).

\section{Control experiments}

Growth cones in the absence of DMSO

N1E-115 cells extend neurites 1-2 d after suspension and replating in the absence of DMSO; however, after $2 \mathrm{~d}$ the neurites are retracted and the cells reenter division. We injected a number of these cells with fura-2. Although $\left[\mathrm{Ca}^{2+}\right]_{i}$ values were lower, the relationship between $\left[\mathrm{Ca}^{2+}\right]_{\mathrm{i}}$ and behavioral state was maintained: soma, $R=1.39 \pm 0.06, n=9,\left[\mathrm{Ca}^{2+}\right]_{\mathrm{i}}=75 \pm 13 \mathrm{~nm}$; growth cones, motile advancing, $R=1.20 \pm 0.02, n=3,\left[\mathrm{Ca}^{2+}\right]_{\mathrm{i}}$ $=37 \pm 4 \mathrm{nM}$; motile nonadvancing, $R=1.25 \pm 0.02, n=7$,
$\left[\mathrm{Ca}^{2+}\right]_{\mathrm{i}}=47 \pm 4 \mathrm{nM}$ (Fig. 7); flattening, $R=1.36 \pm 0.06, n=$ $3,\left[\mathrm{Ca}^{2+}\right]_{\mathrm{i}}=68 \pm 12 \mathrm{nM}$; retracting, $R=1.38 \pm 0.08, n=6$, $\left[\mathrm{Ca}^{2+}\right]_{i}=73 \pm 15 \mathrm{~nm}$. Spatial gradients of $\left[\mathrm{Ca}^{2+}\right]_{i}$ were similar in the presence and absence of DMSO (Fig. 7). As with cells differentiating in the presence of DMSO, soma $\left[\mathrm{Ca}^{2+}\right]_{i}$ was higher than growth cone $\left[\mathrm{Ca}^{2+}\right]_{i}$, although the difference was not significant $\left(R_{\text {growh cone }}-R_{\text {soma }}=-0.02 \pm 0.05, n=9\right)$. We again observed a gradation of $R$ value within the growth cone, with $R$ highest in the center and lower both at the junction with the neurite and at the leading edge (Fig. 7); however, this time only the junction/center difference proved statistically significant $\left(R_{\text {junction }}-R_{\text {center }}=-0.03 \pm 0.01, n=11, p<0.025\right)$. This difference corresponded to a calcium gradient of $5 \mathrm{nM}$. $\left[\mathrm{Ca}^{2+}\right]$ was significantly lower in advancing veils $\left(R_{\text {advancing veil }}-\right.$ $R_{\text {whole growth cone }}=-0.02 \pm 0.01, n=8, p<0.01$, corresponding 
to a $\left[\mathrm{Ca}^{2+}\right]_{\mathrm{i}}$ difference of $\left.3 \mathrm{nM}\right)$. As before, we saw no evidence for raised $\left[\mathrm{Ca}^{2+}\right]_{\mathrm{i}}$ at the base of filopodia $\left(R_{\text {filopodial base }}-\right.$ $R_{\text {whole growth cone }}=-0.02 \pm 0.01, n=6$, not significant).

\section{Injection of $A N T S$}

An apparent correlation of $\left[\mathrm{Ca}^{2+}\right]_{\mathrm{i}}$ and growth cone behavioral state might arise not from real differences of $\left[\mathrm{Ca}^{2+}\right]_{\mathrm{i}}$, but rather might be an artifact caused by factors such as UV absorption, light scattering, or intracellular environment being different in growth cones of different behavioral states. In order to test this, we made ratio measurements on DMSO-differentiated cells using the same excitation and barrier filters but injecting ANTS instead of fura-2. ANTS is a dye with excitation and emission spectra similar to fura- 2 but is unaffected by either $\left[\mathrm{Ca}^{2+}\right]_{\mathrm{i}}$ or $\mathrm{pH}$. As with fura- 2 measurements, $R$ for ANTS was normalized such that $R=1$ for ANTS in the in vitro standard solution. $R$ for intracellular ANTS was consistently $<1$; however, the mean $R$ value was not significantly different in any of the growth cone behavioral groups observed: quiescent, $R=0.81 \pm 0.03, n=$ 4; motile nonadvancing, $R=0.83 \pm 0.01, n=4$; and retracting $R=0.80 \pm 0.04, n=9)(p>0.05$ for all pairs). Therefore, we believe that the different $R$ values we record for fura- 2 in growth cones of different behavioral state are not an artifact of differing geometry or intracellular conditions but do indeed result from different $\left[\mathrm{Ca}^{2+}\right]_{\mathrm{i}}$.

\section{Fura-AM loading}

We examined 31 DMSO-treated growth cones in which fura-2 was introduced into cells not by injection but by incubation in the membrane-permeable ester fura-2 AM using a protocol similar to that of Connor (1986). Cell bodies of AM-loaded cells showed pronounced spatial gradients (Fig. 8), while 7 growth cones showed prominent, discrete high- $\left[\mathrm{Ca}^{2+}\right]_{i}$ regions at the leading edge (Fig. 8). These phenomena were never observed when fura- 2 was introduced by injection. Regional $R$ and, therefore, indicated $\left[\mathrm{Ca}^{2+}\right]$ were considerably higher in AM-loaded cells, while variation of growth cone $\left[\mathrm{Ca}^{2+}\right]_{\mathrm{i}}$ among growth cones of each behavioral state was much greater than when fura- 2 was introduced by injection: soma, $R=1.70 \pm 0.05, n=8,\left[\mathrm{Ca}^{2+}\right]_{\mathrm{i}}$ $=134 \pm 11 \mathrm{nM}$; growth cones, quiescent, $R=1.98 \pm 0.13, n$ $=5,\left[\mathrm{Ca}^{2+}\right]_{\mathrm{i}}=192 \pm 26 \mathrm{nM}$; motile advancing, $R=1.64 \pm 0.11$, $n=9,\left[\mathrm{Ca}^{2+}\right]_{\mathrm{i}}=124 \pm 22 \mathrm{nM}$; motile nonadvancing, $R=1.72$ $\pm 0.12, n=8,\left[\mathrm{Ca}^{2+}\right]_{\mathrm{i}}=140 \pm 24 \mathrm{nM}$; retracting, $R=1.79 \pm$ $0.08, n=11,\left[\mathrm{Ca}^{2+}\right]_{\mathrm{i}}=154 \pm 17 \mathrm{nM}$. In no pair of these growth cone values is the difference statistically significant.

\section{Discussion}

True growth at the growth cone consists of advance at 2 locations. The leading edge of the growth cone moves forward by extending veils (Goldberg and Burmeister, 1986) or by being pulled forward by the tension in filopodia (Bray, 1987). The boundary between the neurite and the growth cone moves forward through an extension of the microtubule/neurofilament cytoskeleton (Goldberg and Burmeister, 1986). We observed true growth only in those growth cones in which $\left[\mathrm{Ca}^{2+}\right]_{\mathrm{i}}$ was lowest. $\left[\mathrm{Ca}^{2+}\right]_{\mathrm{i}}$ in motile, advancing growth cones was not significantly different from $\left[\mathrm{Ca}^{2+}\right]_{\mathrm{i}}$ in quiescent growth cones. Kater et al. (1988) have suggested that a rise of $\left[\mathrm{Ca}^{2+}\right]_{i}$ from the concentration found in quiescent growth cones activates growth and motility. Our results show that this model is unlikely to be true in N1E- 115 cells. Furthermore, the correlation, in motile growth cones, between raised $\left[\mathrm{Ca}^{2+}\right]_{\mathrm{i}}$ and failure of the neurite/growth cone boundary to advance, leads us to believe that raised $\left[\mathrm{Ca}^{2+}\right]_{i}$ opposes extension of the microtubule/neurofilament cytoskeleton within the neurite. Calcium is known to interact with calmodulin and microtubule-associated proteins to inhibit microtubule elongation (Manalan and Klee, 1984). In motile, advancing growth cones, all the activity associated with growth, including filopodial extension, veil advance, ruffling, and advance of the neurite/growth cone junction, occur at low $\left[\mathrm{Ca}^{2+}\right]_{i}$. Thus, raised $\left[\mathrm{Ca}^{2+}\right]_{\mathrm{i}}$ is not essential for any of these processes.

We observed retraction when growth cone $\left[\mathrm{Ca}^{2+}\right]_{i}$ rose to 120 nM and above. The first effect seen as $\left[\mathrm{Ca}^{2}\right]_{i}$ rose was a pulling of motile structures such as veils and ruffles into the main body of the growth cone. If $\left[\mathrm{Ca}^{2+}\right]_{i}$ fell, motility returned. At higher levels of $\left[\mathrm{Ca}^{2+}\right]_{\mathrm{i}}$, the growth cone moved back towards the cell body, as if pulled by tension in the neurite. It is likely that raised $\left[\mathrm{Ca}^{2+}\right]_{i}$ causes retraction. Injection of $\mathrm{Ca}^{2+}$ into growing neuroblastoma cells causes a reversible retraction of motile structures (Bolsover et al., 1988). The conversion of motile growth cones into retracting growth cones often proceeded through a transitional stage we tcrm flattening, during which $\left[\mathrm{Ca}^{2+}\right]_{\mathrm{i}}$ had a value intermediate between the $\left[\mathrm{Ca}^{2+}\right]_{i}$ values characteristic of motile nonadvancing and retracting growth cones. During flattening, growth cones extended veils and, less often, filopodia. Growth cone area increased and the leading edge of the growth cone advanced; however, the boundary between the neurite and the growth cone did not advance. Anglister et al. (1982) observed flattening of growth cones after treatment with calcium ionophore. Our results, together with those of Anglister et al. (1982), show that raised $\left[\mathrm{Ca}^{2+}\right]_{i}$ can promote veil extension, but only at $\left[\mathrm{Ca}^{2+}\right]_{\mathrm{i}}$ levels that are nonpermissive for neurite growth. A possible physiological role for $\left[\mathrm{Ca}^{2+}\right]_{\mathrm{i}}$-induced veil extension is reorientation of the growth cone by external stimuli; such stimuli might cause a transient, local increase of $\left[\mathrm{Ca}^{2+}\right]_{i}$ that promoted local veil extension; when $\left[\mathrm{Ca}^{2+}\right]_{\mathrm{i}}$ fell again, growth might resume in the new direction. We observed many growth cones that passed directly from the motile nonadvancing state to retraction; in these growth cones, the first effect of raised $\left[\mathrm{Ca}^{2+}\right]_{\mathrm{i}}$ was not extension of veils and ruffles but rather a pulling in of these structures. It is possible that the nature of the initial effect of raised $\left[\mathrm{Ca}^{2+}\right]_{i}$, flattening or retraction, depends on the precise

Figure 7. Growth cone in the absence of DMSO. A, Fura-2 ratio image of a motile nonadvancing growth cone of a cell plated and measured in the absence of DMSO. Overall $R=1.10,\left[\mathrm{Ca}^{2+}\right]_{\mathrm{i}}=19 \mathrm{nM}$. The time of acquisition of this image was defined as 0 min. Mean $R$ in the region of advancing veils (distal to, and including, the 4 prominent dark spots that form a line across the growth cone in $B$ ) was 1.10 , equal to the mean for the whole growth cone. $B$, Transmitted light image acquired $21 \mathrm{sec}$ later. $F$, Filopodia. The yellow lines indicating filopodia are placed in the same position in images $A$ and $B . B$, neurite/growth cone boundary. $C$, Fura-2 ratio image acquired 10 min after image $A$. Overall $R=1.12$, $\left[\mathrm{Ca}^{2+}\right]_{\mathrm{i}}=$ $22 \mathrm{nM}$. Mean $R$ in the region of advancing veils (distal to, and including, the 4 prominent dark spots that form a line across the growth cone in $D$ ) was $1.10,\left[\mathrm{Ca}^{2+}\right]_{\mathrm{i}}=19 \mathrm{nM}$, less than the mean for the whole growth cone. $D$, Transmitted light image acquired 31 sec after image $C$. $V$, advancing veils. The yellow lines indicating veils are placed in the same position in images $C$ and $D, E, 42$ min after acquisition of image $A$, the veils have advanced further; however, the growth cone/neurite boundary $(B$, yellow line in same position as in image $B)$ has not advanced. A growth cone from a cell differentiating in the presence of DMSO would have been expected to be either quiescent or motile advancing at such a low [Ca $\left.{ }^{2+}\right]_{i}$. 

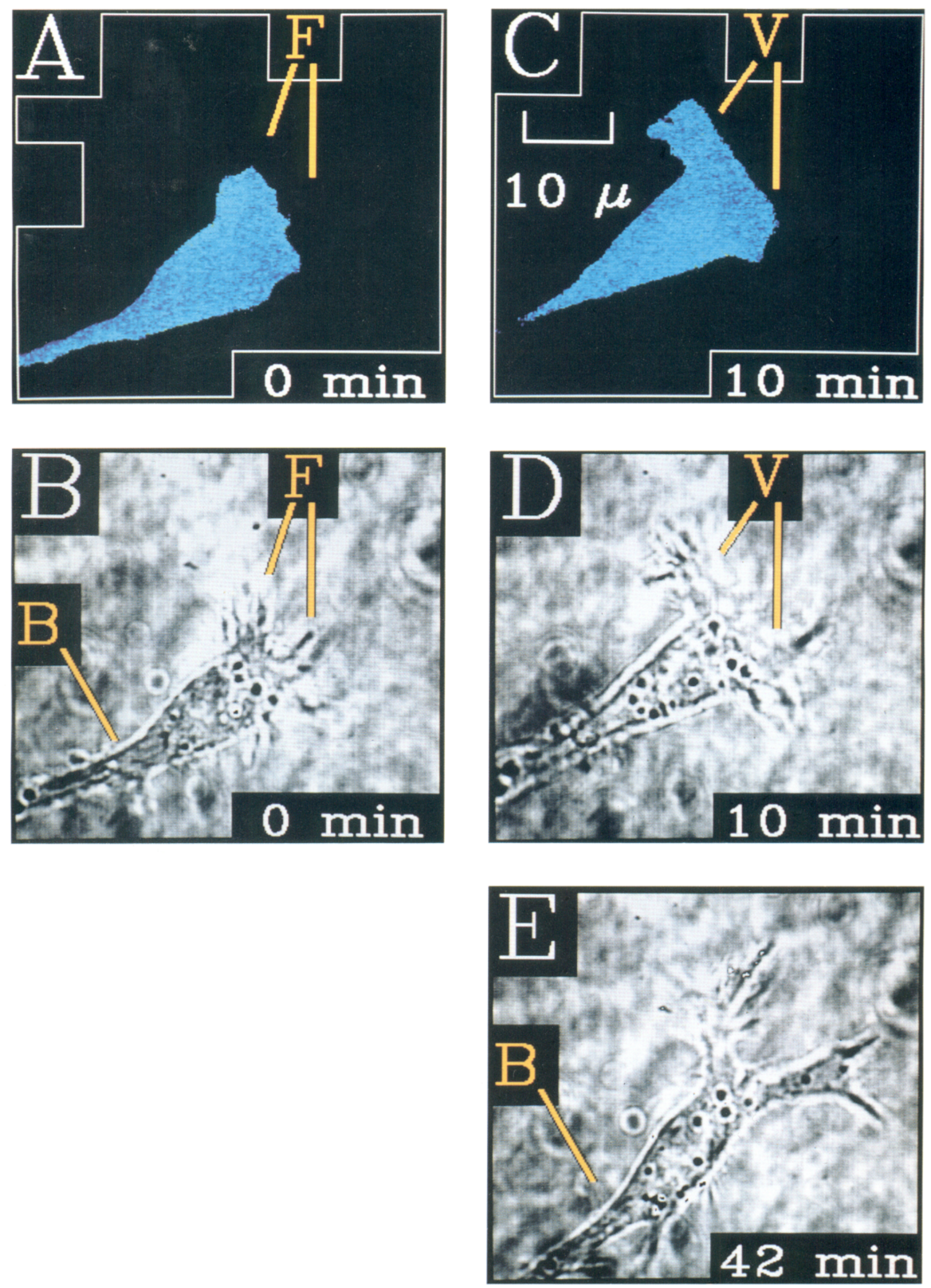


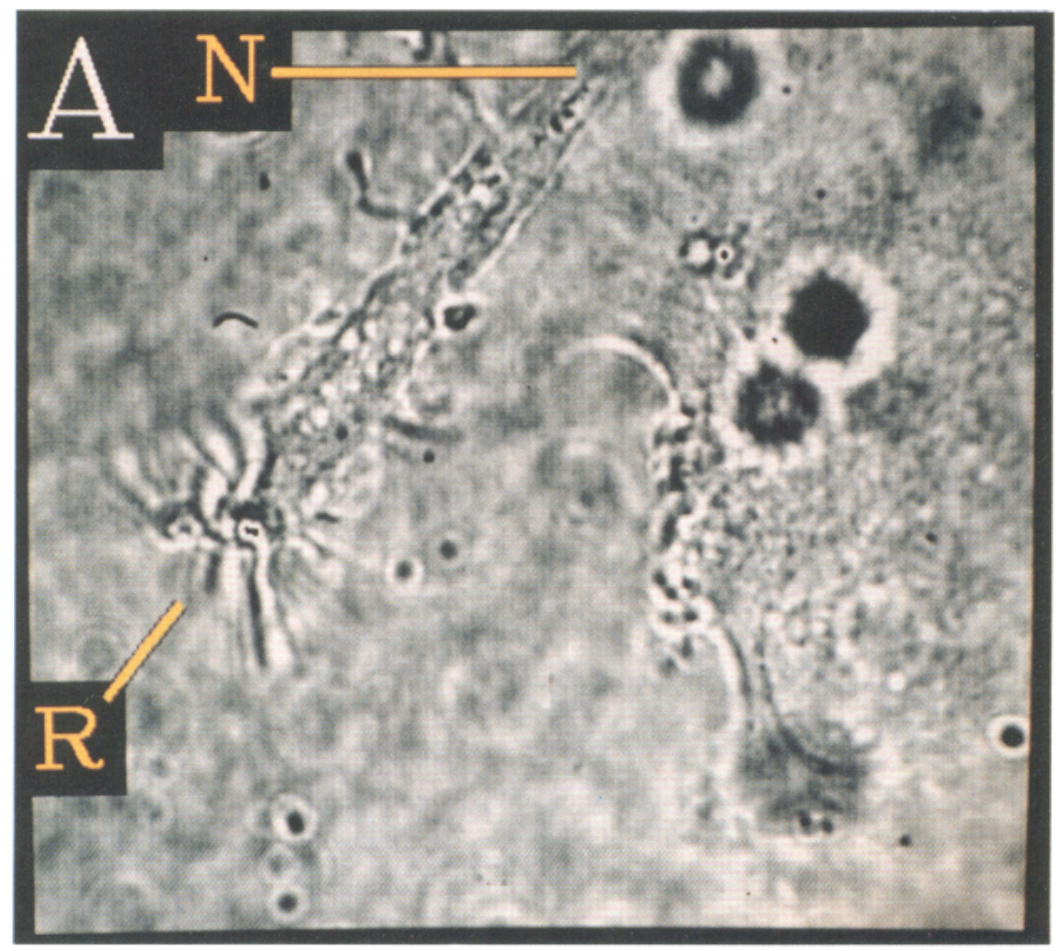

Figure 8. Pronounced apparent $\left[\mathrm{Ca}^{2+}\right]_{\mathrm{i}}$ spatial gradients in cells loaded by incubation in fura-2 AM. $A$, A neurite $(N)$ of one cell terminates in a growth cone with a prominent ruffle $(R)$. The flattened cell body of a second cell lies to the right of the growth cone. $B$, Fura-2 ratio image acquired $24 \mathrm{sec}$ after image $A$. Small, discrete regions with high indicated $\left[\mathrm{Ca}^{2+}\right]_{i}$ as seen here in both the growth cone and cell body were never observed in cells injected with fura-2.

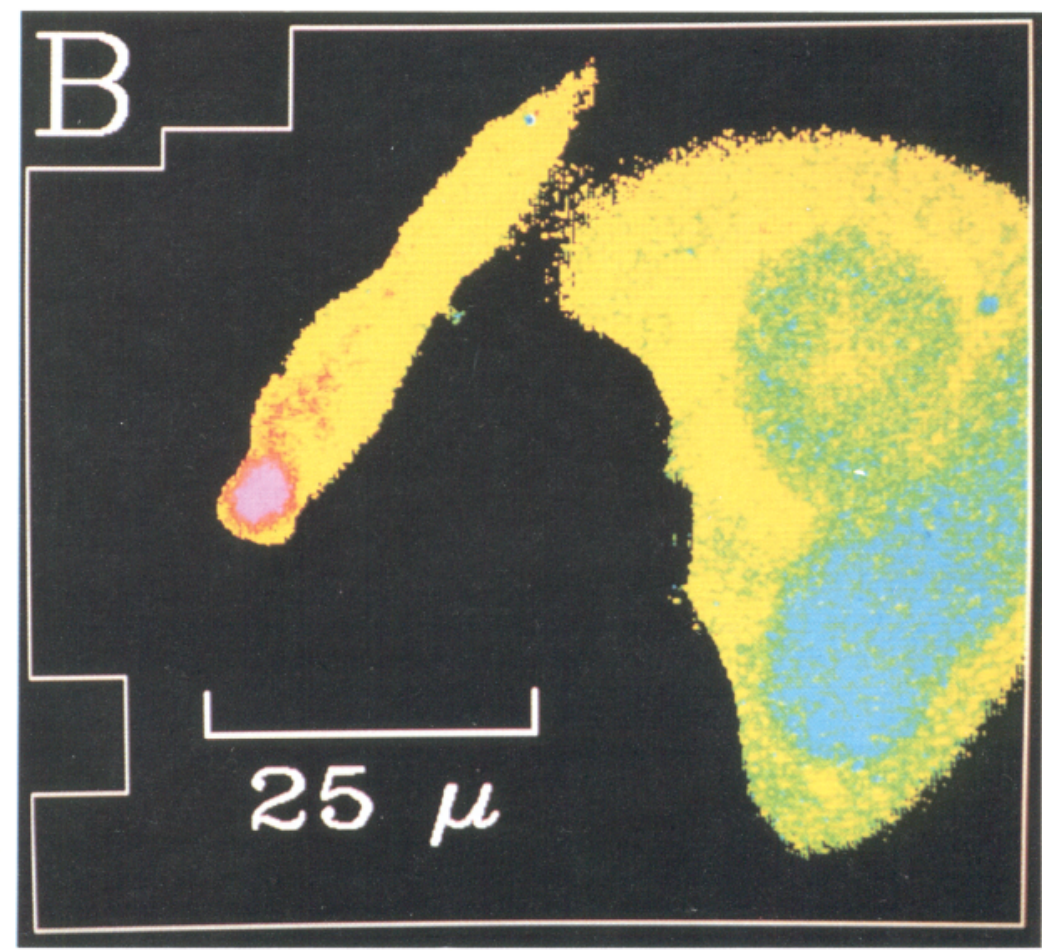

layout of cytoskeleton within the growth cone, and the extent to which different parts of the cytoskeleton are exposed to raised $\left[\mathrm{Ca}^{2+}\right]_{\text {. }}$.

Several authors have suggested that local regions of raised $\left[\mathrm{Ca}^{2+}\right]_{\mathrm{i}}$ may occur within growth cones and may trigger local events. Connor (1986) found local regions of high $\left[\mathrm{Ca}^{2+}\right]_{i}$ at the base of extending filopodia. Goldberg (1988) suggested that veil extension might occur from regions of the growth cone in which
$\left[\mathrm{Ca}^{2+}\right]_{\mathrm{i}}$ was locally high. We never observed local elevations of $\left[\mathrm{Ca}^{2+}\right]_{\mathrm{i}}$ within motile structures or at the base of filopodia. Rather, where gradients exist, we find $\left[\mathrm{Ca}^{2+}\right]$, to be on average 5-10 nm lower within motile structures. It is unlikely that such small $\left[\mathrm{Ca}^{2+}\right]_{\mathrm{i}}$ gradients have any physiological role. Although it is possible that the local regions of low $\left[\mathrm{Ca}^{2+}\right]_{\mathrm{i}}$ trigger the production of motile structures, it is equally possible that motile regions, perhaps by virtue of their high surface area/volume ratio, may 


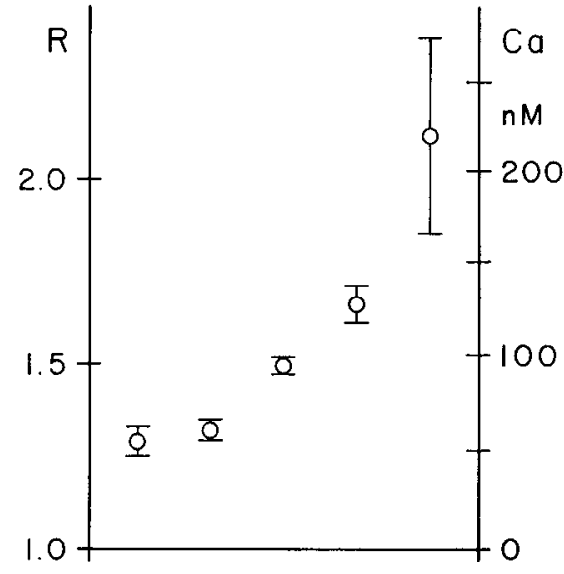

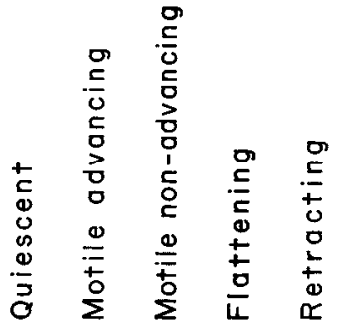

Figure 9. Mean $R$ values, with corresponding $\left[\mathrm{Ca}^{2+}\right]_{\text {, }}$, for the 5 behavioral states described in this paper. Only growth cones of cells differentiated with DMSO and injected with fura-2 are included. Furthermore, growth cones that could not be placed unequivocally in 1 of the 5 behavioral states were not used in the calculation of these means. Range bars are $\pm 1 \mathrm{SE}$. Number of growth cones (left to right) $=8,7$, 20,9 , and 7 , respectively.

create a low $\left[\mathrm{Ca}^{2+}\right]_{\text {in }}$ within themselves. Although we suggest above that local regions of high $\left[\mathrm{Ca}^{2+}\right]_{i}$ may promote local veil advance under other conditions, our results demonstrate that all types of motility, including veil advance, can occur in the absence of locally elevated $\left[\mathrm{Ca}^{2+}\right]_{\mathrm{i}}$. Thus, under our conditions the site at which motility occurs is dependent on factors other than locally raised $\left[\mathrm{Ca}^{2+}\right]_{\text {. }}$.

Connor (1986) and Cohan et al. (1987) used digital imaging fluorescence microscopy to examine neurons loaded with fura-2 by bathing in the membrane-permeable ester fura- $2 \mathrm{AM}$. Some of their conclusions were very different from ours. They proposed that a rise of $\left[\mathrm{Ca}^{2+}\right]_{i}$ above the level found in quiescent growth cones promotes motility and growth (Kater et al., 1988). Connor (1986) found large gradients of $\left[\mathrm{Ca}^{2+}\right]_{\mathrm{i}}$ within the cell body and within the growth cone, with local regions of elevated $\left[\mathrm{Ca}^{2+}\right]_{i}$ at the base of extending filopodia. These discrepancies may result partly from the method of dye loading used. When fura-2 is loaded by bathing cells in medium containing the membrane permeable ester, fura-2 AM, intracellular organelles such as endocytotic and secretory vesicles load with dye (Almers and Neher, 1985; Cobbold and Rink, 1987). Regions of cytoplasm rich in organelles therefore appear to have a locally high $\left[\mathrm{Ca}^{2+}\right]_{\text {i, }}$, even though the cytoplasmic $\left[\mathrm{Ca}^{2+}\right]_{\mathrm{i}}$ may be uniform. The perinuclear high-Ca ${ }^{2+}$ ring in the cell on the right of Figure 8 is characteristic of this type of artifact, and probably results from endocytosis of dye micelles (Cobbold and Rink, 1987). It is likely that the high- $\mathrm{Ca}^{2+}$ regions at the tip of growth cones loaded with fura-2 AM, but never seen in fura-2-injected growth cones, are a similar artifact as the leading edge of growth cones is a site of active endocytosis (Bunge, 1977). Variation of apparent
$\left[\mathrm{Ca}^{2+}\right]_{i}$ was much larger in AM-loaded growth cones compared with growth cones of cells injected with fura-2, possibly because of differences in the degree to which intracellular orgenelles loaded with dye.

An equally important cause of our different conclusions may be interpretation of growth cone behavioral states. The growth cones we class as motile advancing fit the generally accepted pattern of growth cone growth (Goldberg and Burmeister, 1986; Bray, 1987). We suggest that Connor (1986) and Cohan et al. (1987) may have included within their growing category growth cones that we would categorize as belonging to another behavioral state. We class the behavior of the growth cones in which the leading edge advanced as either motile nonadvancing or flattening unless the growth cone/neurite junction also moved forward. We regard only that subgroup of motile growth cones in which the neurite/growth cone junction moved forward as truly growing. In contrast, Cohan et al. (1987) do not distinguish between motile advancing growth cones, in which the boundary between the neurite and the growth cone moves forward, and motile nonadvancing growth cones, in which the boundary does not move. If we combine our data from motile advancing, motile nonadvancing, and flattening growth cones, then $\left[\mathrm{Ca}^{2}{ }^{2}\right]_{i}$ is significantly higher in the broad motile group (motile: $R=1.49$ $\pm 0.03, n=37,\left[\mathrm{Ca}^{2+}\right]_{\mathrm{i}}=94 \pm 6 \mathrm{nM}$; quiescent: $R=1.29 \pm$ $\left.0.04, n=8, p<0.001),\left[\mathrm{Ca}^{2+}\right]_{\mathrm{i}}=55 \pm 7 \mathrm{nM}\right)$. We are therefore in agreement with Cohan et al. (1987) in that we also find $\left[\mathrm{Ca}^{2+}\right]_{\mathrm{i}}$ to be higher in motile growth cones. However, since we observe behavior of the type we term motility (extension and movement of filopodia, veils, or ruffles) equally in motile, advancing growth cones, with the lowest $\left[\mathrm{Ca}^{2+}\right]_{i}$, and in motile, nonadvancing growth cones, at a higher $\left[\mathrm{Ca}^{2+}\right]_{i}$, we do not believe that raised $\left[\mathrm{Ca}^{2+}\right]_{i}$ causes motility.

The majority of our results were obtained using N1E-115 cells differentiated with DMSO (Kimhi et al., 1976); therefore, they might not be typical of other growth cones. DMSO causes a significant reduction in the concentration of $3^{\prime}, 5^{\prime}$ cyclic adenosine monophosphate (CAMP) within N1E-115 cells (Kimhi et al., 1976). Furthermore, DMSO might disrupt $\left[\mathrm{Ca}^{2+}\right]_{i}$ gradients, perhaps by distorting the structure of the cell membrane. However, we obtain very similar results in growth cones of N1E115 cells grown and measured in the absence of DMSO. Our results are therefore not an artefact of DMSO treatment.

Our results show that the various processes occurring at the growth cone are differentially sensitive to $\left[\mathrm{Ca}^{2+}\right]$. Veil extension can be promoted by raised $\left[\mathrm{Ca}^{2+}\right]_{\mathrm{i}}$. Ruffling is insensitive to $\left[\mathrm{Ca}^{2+}\right]_{i}$ until $\left[\mathrm{Ca}^{2+}\right]_{i}$ rises to levels that cause retraction. Advance of the neurite/growth cone boundary requires low calcium.

\section{References}

Almers, W., and E. Neher (1985) The calcium signal from Fura-2 loaded mast cells depends strongly on the method of dye loading. FEBS Lett. 192: 13-18.

Anglister, L., I. C. Farber, A. Shahar, and A. Grinvald (1982) Localization of voltage-sensitive calcium channels along developing ncurites: Their possible role in regulating neurite elongation. Dev. Biol. 94: 351-365.

Argiro, V., M. B. Bunge, and M. I. Johnson (1985) A quantitative study of growth cone filopodial extension. J. Neurosci. Res. 13: 149162.

Bambury, J. R., D. Bray, and K. Chapman (1986) Assembly of microtubules at the tip of growing axons. Nature 321: 788-790.

Baylor, S. M., and S. Hollingworth (1988) Fura-2 calcium transients in frog skeletal muscle fibres. J. Physiol. (Lond.) 209: 151-192.

Bolsover, S. R., S. Gilbert, and I. Spector (1988) Motility at the growth 
cone of N1E-115 neuroblastoma cells: Effect of $\mathrm{Ca}++$ injection. J Physiol. (Lond.) 407: 86P.

Bray, D. (1987) Growth cones: Do they pull or are they pushed? Trends Neurosci. 10: 431-434.

Bunge, M. B. (1977) Initial endocytosis of peroxidase or ferritin by growth cones of cultured nerve cells. J. Neurocytol. 6: 407-439.

Cobbold, P. H., and T. J. Rink (1987) Fluorescence and bioluminescence measurement of cytoplasmic free calcium. Biochem. J. 248: 313-328.

Cohan, C. S., and S. B. Kater (1986) Suppression of neurite elongation and growth cone motility by electrical activity. Science 232 : 1638 1640.

Cohan, C. S., J. A. Connor, and S. B. Kater (1987) Electrically and chemically mediated increases in intracellular calcium in neuronal growth cones. J. Neurosci. 7: 3588-3599.

Connolly, J. L., P. J. Seeley, and L. A. Greene (1985) Regulation of growth cone morphology by nerve growth factor: A comparative study by scanning electron microscopy. J. Neurosci. Res. 13: 183-198.

Connor, J. A. (1986) Digital imaging of free calcium changes and of spatial gradients in growing processes in single, mammalian central nervous system cells. Proc. Nat. Acad. Sci. USA 83: 6179-6183.

Freeman, J. A., P. B. Manis, G. J. Snipes, B. N. Mayes, P. C. Samson, J. P. Wikswo, and D. B. Freeman (1985) Steady growth cone currents revealed by a novel vibrating probe: $A$ possible mechanism underlying neurite growth. J. Neurosci. Res. 13: 257-283.

Goldberg, D. J. (1988) Local role of $\mathrm{Ca}^{++}$in formation of veils in growth cones. J. Neurosci. 8: 2596-2605.

Goldberg, D. J., and D. W. Burmeister (1986) Stages in axon formation: Observations of growth of Aplysia axons in culture using video-enhanced contrast-differential interference contrast microscopy. J. Cell. Biol. 103: 1921-1931.

Grant, N. J., C. Oriol-Audit, and M. J. Dickens (1983) Supramolecular forms of actin induced by polyamines: An electron microscopic study. Eur. J. Cell Biol. 30: 67-73.

Greene, L. A., and E. M. Shooter (1980) The nerve growth factor: Biochemistry, synthesis and mechanism of action. Annu. Rev. Neurosci. 3: 353-402.

Grynkiewicz, G., M. Poenie, and R. Y. Tsien (1985) A new generation of $\mathrm{Ca}^{++}$indicators with greatly improved fluorescence properties. J. Biol. Chem. 260: 3440-3450.

Gundersen, R. W., and J. N. Barrett (1980) Characterization of the turning response of dorsal root neurites toward nerve growth factor. J. Cell Biol. 87: 546-554.
Hammarback, J. A., S. L. Palm, L. T. Furcht, and P. C. LeTourneau (1985) Guidance of neurite outgrowth by pathways of substratumabsorbed laminin. J. Neurosci. Res. 13: 213-220.

Kater, S. B., C. S. Cohan, G. A. Jacobs, and J. P. Miller (1986) Image intensification of stained, functioning and growing neurons. In Optical Methods in Cell Physiology, B. Salzberg and P. DeWeer, eds., pp. 3150, Wiley, New York.

Kater, S. B., M. P. Mattson, C. Cohan, and J. Connor (1988) Calcium regulation of the neuronal growth cone. Trends Neurosci. 11:315321.

Kimhi, Y., C. Palfrey, I. Spector, Y. Barak, and U. Z. Littauer (1976) Maturation of neuroblastoma cells in the presence of dimethylsulphoxide. Proc. Nat. Acad. Sci. USA 73: 462-466.

Lasek, R. J (1982) Dynamic properties of cytoskeletons. Neurosci. Res. Prog. Bull. 19: 7-153.

Manalan, A. S., and C. B. Klee (1984) Calmodulin. Adv. Cyclic Nucleotide Protein Phosphorylation Res. 18: 227-278.

Matus, A. (1988) Microtubule-associated proteins: Their potential role in determining neuronal morphology. Annu. Rev. Neurosci. 11: 2944.

McCobb, D. P., P. G. Haydon, and S. B. Kater (1988) Dopamine and serotonin inhibition of neurite elongation of different identified neurons. J. Neurosci. Res. 19: 19-26.

McCaig, C. D. (1988) Nerve guidance: A role for bio-electric fields. Prog. Neurobiol. 30: 449-468.

Nasi, E., and D. Tillotson (1985) The rate of diffusion of $\mathrm{Ca}^{2+}$ and $\mathrm{Ba}^{2+}$ in a nerve cell body. Biophys. J. 47: 735-738.

Schubert, D. (1984) Developmental Biology of Cultured Nerve, Muscle and Glia, Wiley, New York.

Tusney, K. W., and N. K. Wessels (1983) Neuronal motility: The ultrastructure of veils and microspikes correlates with their motile activities. J. Cell. Sci. 61: 389-411.

Tsien, R. Y. (1980) New calcium indicators and buffers with high selectivity against magnesium and protons: Design, synthesis, and properties of prototype structures. Biochemistry 19: 2396-2404.

Tsien, R. Y. (1981) A non-disruptive technique for loading calcium buffers and indicators into cells. Nature 290: 527-528.

Tsien, R. Y., and M. Poenie (1986) Fluorescence ratio imaging: A new window into intracellular ionic signalling. Trends Biochem. Sci. 11. $450-455$. 